\title{
Instant and Early Efficacy of Gamma Knife Treatment on Trigeminal Neuralgia
}

\author{
(1) Ayşe ALTINOK,, 4 (1) Türker KARANCI, ${ }^{2}$ (b) Arif ÖZBEK, ${ }^{3}$ (D) Serdar Baki ALBAYRAK ${ }^{2,3}$ \\ 'Department of Radiation Oncology, Medipol University, İstanbul-Turkey \\ ${ }^{2}$ Department of Neurosurgery, İstanbul Aydın University, İstanbul-Turkey \\ ${ }^{3}$ Department of Neurosurgery, Medipol University, İstanbul-Turkey \\ ${ }^{4}$ Department of Radiation Oncology, Acıbadem Maslak Hospital, İstanbul-Turkey
}

\begin{abstract}
OBJECTIVE
Trigeminal neuralgia (TN) is a common craniofacial pain syndrome manifested by the episodes of severe lancinating pain along the sensory region of the trigeminal nerve. Vascular compression theory has been postulated as the main cause of TN in the root entry zone of the trigeminal nerve. Microvascular decompression surgery is the most effective surgical option for the treatment of TN. Gamma knife surgery (GKS) is a minimally invasive treatment for drug-resistant trigeminal neuralgia (TN). We aimed to investigate the instant and early pain relief in 12 consecutive patients.
\end{abstract}

\section{METHODS}

This clinical study was conducted at the Department of Radiation Oncology, Medipol University, Turkey. The patient population consisted of 12 consecutive patients having medically refractory TN, with a median age of 60.5 (ranging from 50 to 77 years). Patients underwent GKS between March and January 2016, using the Gamma Knife Perfexion Model. A single $4 \mathrm{~mm}$ isocenter was positioned in the cisternal portion of the trigeminal nerve, and the mean maximum dose of $65 \mathrm{~Gy}$ (60-70 Gy) was delivered.

\section{RESULTS}

Satisfactory pain relief without any major complications was evident in all patients. The pain relief started after 1 hour to 3 days following the gamma knife procedure.

\section{CONCLUSION}

As a novel contribution to the relevant literature, instant and early pain relief was evident in all patients. In this context, a randomized prospective clinical trial with a larger patient population is necessary to optimize the instant and early efficacy of GKS in the treatment of TN.

Keywords: Gamma knife; radiosurgery; trigeminal neuralgia.

Copyright $\odot$ 2018, Turkish Society for Radiation Oncology

\section{Introduction}

Trigeminal neuralgia (TN) (i.e., tic douloureux) is a severe paroxysmal facial pain along the sensory region of the trigeminal nerve. It is more prevalent in women $(6 / 100.000)$ than men $(3.5 / 100.000)$. The most commonly used classification scheme for facial pain is the Burchiel classification [1,2] (Table 1). Classical idiopathic TN-Type 1 neuralgia-is defined as the facial pain that is episodic at least $50 \%$ of the time. The pathopyhsiology of idiopathic TN has been explained by the "vascular hypothesis" in which the offending vessels-mostly the superior cerebellar artery and its branches-compress the trigeminal nerve, causing the 
Table 1 Burchiel Classification Scheme for Facial Pain

\begin{tabular}{lc} 
Burchiel pain type & Clinical history \\
\hline $\begin{array}{l}\text { Type I trigeminal neuralgia } \\
\text { Type II trigeminal neuralgia }\end{array}$ & $>50 \%$ episodic pain \\
Trigeminal & $<50 \%$ episodic pain \\
neuropathic pain & $\begin{array}{c}\text { Caused by unintentional } \\
\text { trauma (e.g., tooth extraction) }\end{array}$ \\
$\begin{array}{l}\text { Trigeminal } \\
\text { deafferentation pain }\end{array}$ & $\begin{array}{c}\text { Caused by intentional trauma } \\
\text { (e.g., rhizotomy) }\end{array}$ \\
$\begin{array}{l}\text { Symptomatic trigeminal } \\
\text { neuralgia }\end{array}$ & Multiple sclerosis \\
Postherpetic neuralgia & Herpes zoster outbreak in \\
trigeminal distribution \\
Atypical facial pain
\end{tabular}

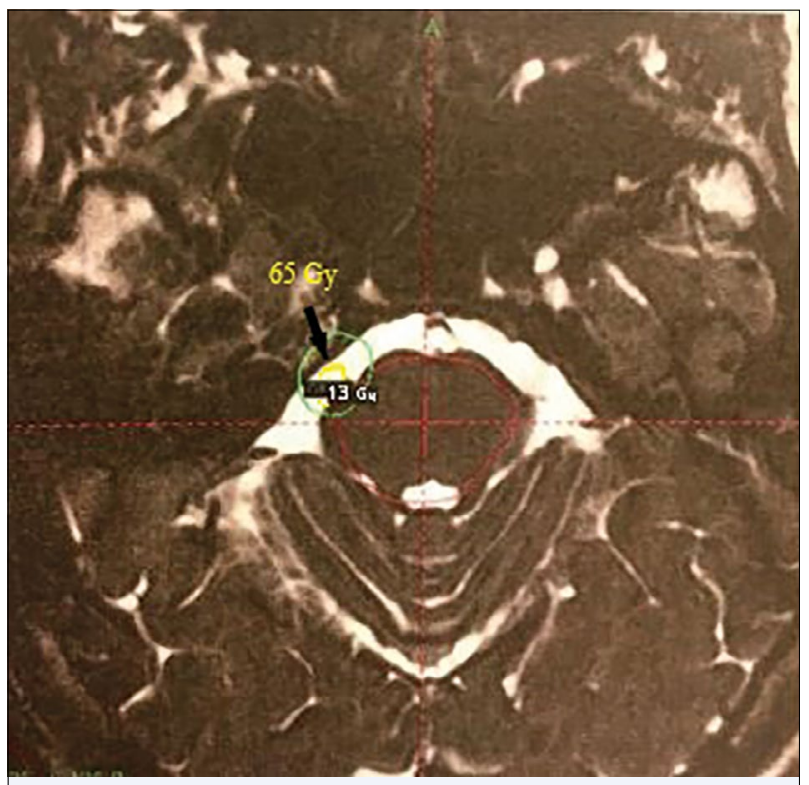

Fig. 1. Gamma Knife plan. The target is the pars triangularis.

episodic facial pain. The first-line treatment for TN is medications including antiepileptics, tricyclic antidepressants, benzodiazepines, and narcotics in selected cases. Carbamazepine (Tegretol, Novartis International AG, Basel, Switzerland) is currently the most effective drug in the treatment of TN.[3,4] However, it is almost always inevitable that most of the patients become refractory to medications in a few years following the disease onset. These patients eventually require percutaneous ablative or surgical treatment. Additionally, medication intolerance and associated toxicity, including sedation, ataxia, and cognitive changes, are other major drawbacks. Percutaneous ablative techniques of the Gasserian ganglion include radiofrequency, glycerol, and balloon rhizotomies. These techniques are advantegous in that they generally do not require general anesthesia, and the pain relief is immediate. However, the risk of anesthesia dolorosa or hypesthesia is higher in these percutaneous procedures.

Microvascular decompression (MVD) is a surgical technique utilizing a sub-occipital retrosigmoid coin craniotomy and decompression of the trigeminal nerve from the offending vasculature. The placement of a piece of muscle or teflon between the trigeminal nerve and the offending vessel helps to prevent the recurrent vascular compression.

Jannetta et al. popularized the MVD operation in the treatment of TN. Likewise, Barker et al., reported the effectiveness of MVD by demonstrating a $70 \%$ cure rate in a 10-year follow-up study.[3] Surgical morbidity and mortality of MVD is generally quite low; However, it becomes riskier in patients over 60 years of age or those with bleeding diathesis or comorbities.[4]

Gamma knife surgery (GKS) has been a treatment option for TN, especially in the last two decades. The non-invasiveness and low morbidity rate offer a useful treatment alternative for elderly patients. The major disadvantage of GKS is its limited durability of satisfactory pain control with a median time of 5 years. $[3,4,5]$

\section{Materials and Methods}

An Ethics Committee approval for the study was received from the Institution. Our patient population consisted of 8 males and 4 females, with a mean age of 62 years. All patients had been treated with more than one pharmacological agent, and all were refractory to medical treatment at the time of admission with severe facial pain under medical treatment. None had undergone percutaneous ablative procedures or MVD surgery. We used the Gamma Knife Perfexion Model at the Department of Radiation Oncology, Medipol University between March 2015 and January 2016. Three Tesla magnetic resonance images were obtained. A single $4 \mathrm{~mm}$ isocenter was positioned in the cisternal portion of the trigeminal nerve, and a mean maximum dose of 65 Gy (60-70 Gy) was delivered (Fig. 1). Duration of the procedure ranged from 3 to 4 hours (mean, 3.5 hours). All patients were discharged on the same day and examined at the 1st and 7th day and the 1st month following GKS. An improvement in the pain intensity was evaluated using the Barrow Neurologic Institute Pain Intensity Scale (Table 2). 
Table 2 Barrow Neurologic Institute Pain Intensity Scale

\begin{tabular}{lc} 
Pain Score & Degree of Pain \\
\hline BNII & $\begin{array}{c}\text { Complete pain relief without } \\
\text { medications } \\
\text { BNI II }\end{array}$ \\
BNI III & $\begin{array}{c}\text { Some pain, but not requiring } \\
\text { medications }\end{array}$ \\
BNI IV & $\begin{array}{c}\text { Some pain, but adequately } \\
\text { controlled with medications } \\
\text { Some pain, but inadequately } \\
\text { controlled with medications } \\
\text { Continued severe pain or no } \\
\text { pain relief }\end{array}$ \\
\hline
\end{tabular}

Acronyms: Barrow Neurologic Institute, BNI

\section{Results}

Demographics, complaints, and the pain scores of the patients are depicted in Table 3. All patients started to experience some degree of pain relief starting from the 1 st day following the procedure with a 1- to 2-point decrease in the pain intensity. At the 1 st month examination, 4 patients (33\%) were totally pain free without any medication, while other $8(67 \%)$ were able to control TN satisfactorily with medications. Notably, 2 of the patients (\#9 and \#10 in Table 3 ) experienced a remarkable pain relief immediately after the procedure in the outpatient room. There were no major or minor complications, including paresthesia and hypesthesia.

The median follow-up period of the study was 23 months (min. 13, max. 32 months). Out of 12 patients,
11 were leading pain-free lives without medication. Only 1 patient had the recurrence of pain 14 months after GKS, and the pain was amenable using medication.

\section{Discussion}

There are several treatment options for drug-resistant $\mathrm{TN}$, and GKS is currently considered to be the least invasive neurosurgical approach. GKS was first used in the TN treatment in the 1960s by Lars Leksell, and it started to be more commonly used since early 1990s. Kondziolka et al. examined the efficacy and safety of GKS in TN in a multicentric study in 1996. [4] In addition, development of a high-resolution magnetic resonance imaging enabled a more accurate visualization and targeting of the cisternal portion of the trigeminal nerve.

The current approach is to place a radiosurgical 4 $\mathrm{mm}$ isocenter onto the trigeminal nerve as it is traversing the prepontine cistern. This treatment plan enables the precise targeting of trigeminal nerve, while minimizing the risk of damage to surrounding structures, such as the brainstem and temporal lobe. Likewise, Kondziolka et al. reported that the dorsal root entry zone is more radiosensitive than the more distal segments of the trigeminal nerve because of the more radiosensitive oligodendrocytes ensheathing the nerve proximally.[5,6] However, recent series demonstrated a comparable pain relief when the more distal portion of the nerve such as the pars triangularis (i.e., the

\begin{tabular}{|c|c|c|c|c|c|c|c|c|}
\hline Patients & Gender & Age & $\begin{array}{c}\text { Side/ } \\
\text { Distrubition }\end{array}$ & $\begin{array}{c}\text { Maximum } \\
\text { Dose/GY }\end{array}$ & $\begin{array}{c}\text { BNI Pain } \\
\text { Intensity } \\
\text { Scale/PreOp }\end{array}$ & $\begin{array}{c}\text { BNI Pain } \\
\text { Intensity Scale/ } \\
\text { PostOp on } \\
1^{\text {st }} \text {. day }\end{array}$ & $\begin{array}{l}\text { BNI Pain } \\
\text { Intensity } \\
\text { ScalePostOp } \\
\text { on } 7^{\text {th }} \text {. day }\end{array}$ & $\begin{array}{c}\text { BNI Pain } \\
\text { Intensity } \\
\text { Scale/PostOp } \\
\text { on } 1^{\text {st }} \text {. month }\end{array}$ \\
\hline 1 & Female & 77 & Right/V3 & 70 & 5 & 4 & 3 & 3 \\
\hline 2 & Male & 53 & Left/V1 & 70 & 5 & 4 & 4 & 3 \\
\hline 3 & Male & 71 & Rigth/V1+V2 & 60 & 5 & 3 & 3 & 3 \\
\hline 4 & Female & 60 & Left/V3 & 60 & 5 & 3 & 3 & 3 \\
\hline 5 & Male & 53 & Right/V2+V3 & 65 & 5 & 4 & 4 & 3 \\
\hline 6 & Male & 73 & Rigth/V3 & 60 & 5 & 4 & 4 & 3 \\
\hline 7 & Male & 60 & Right/V2+V3 & 70 & 5 & 3 & 3 & 1 \\
\hline 8 & Male & 50 & Right/V2+V3 & 70 & 5 & 3 & 3 & 1 \\
\hline 9 & Male & 61 & Right/V1 & 65 & 5 & 3 & 3 & 1 \\
\hline 10 & Male & 69 & Right/V1+V2 & 65 & 5 & 3 & 3 & 1 \\
\hline 11 & Female & 62 & Right/V1 & 70 & 5 & 4 & 3 & 3 \\
\hline 12 & Female & 55 & Right/V1+V2 & 70 & 5 & 4 & 3 & 3 \\
\hline
\end{tabular}

Acronyms: Barrow Neurologic Institute, BNI 
transdural segment contained in the Meckel cave) was targeted. Current approach favors the pars triangularis since it is relatively distal to pons but still covers the main nerve trunk before branching. Similarly, we also chose the pars triangularis as the optimum isocenter location with the $20 \%-23 \%$ isodose line tangential to pons with no resultant paresthesia or hypesthesia. On the contrary, Marshall et al. recently reported that patients receiving 80 Gy with a proximal isocenter $(50 \%$ isodose line entering brainstem) experienced a greater durability of pain relief than those with a distal isocenter on the pars triangularis (20\% isodose line tangential to the brainstem).[7]

The efficacy of GKS in TN is generally evaluated by several parameters, including pain relief, being medication free, and an improvement in the quality of life. Régis et al. reported that $70 \%$ of patients were able to come off medications after GKS.[8] Marshall et al. reported a $86 \%$ response to pain within 3 months following GKS.[6] Additionally, Marshall et al. reported a median durability of 4.9 years for patients with classical Type-1 trigeminal neuralgia after GKS.[7] Lucas et al. claimed that an early successful response and cutting off the medications were the significant factors predictive of a longer pain relief after GKS.[6] In addition, Kondziolka et al. published that the post-radiosurgical paresthesia was a major factor predicting the treatment success, while Maesawa et al. reported that the prior MVD surgery and radiofrequency ablation appeared to decrease the treatment efficacy.[4,9] Notably, Brisman et al. claimed that the visualization of contact between a blood vessel and the trigeminal nerve predicts a better response after GKS.[10] Additionally, Balamucki et al. concluded that the dosage of radiation delivered by GKS was not a significant factor with regard to the degree of pain relief.[11] In accordance with the current data in the literature, we were able to manage the pain relief by applying average doses of radiation-65 Gy mean. This approach also minimized the risk of radiosurgical toxicity on the sensory fibers in TN. Kondziolka et al. reported that the mechanism of pain relief is focal axonal degeneration of the trigeminal nerve that the pain fibers are more prone to axonal degeneration than the sensory fibers.[5]

Lastly, Sheehan and Régis et al. reported that the effect of GKS on TN starts between 1 to 180 days in large cohorts.[8,12] However, the time range is so great, and it needs to be optimized by further studies so as to offer GKS as a more reliable and quick-acting alternative in the treatment of GKS in selected patients over MVD and percutaneous procedures.

\section{Conclusion}

GKS is as a safe, effective, and non-invasive treatment option for TN in elderly or debilitated patients with medical co-morbidities or those unwilling to undergo MVD. Factors related to the instant efficacy of GKS on TN need to be clarified by further clinical series.

Peer-review: Externally peer-reviewed.

Conflict of Interest: None declared.

Ethics Committee Approval: An Ethics Committee approval for the study was received from the Institution.

Financial Support: None declared.

Authorship contributions: Concept - S.B.A.; Design - A.A., S.B.A.; Supervision - S.B.A.; Materials - A.Ö.; Data collection \&/or processing - A.Ö., T.K.; Analysis and/or interpretation A.A.; Literature search - T.K.; Writing - A.A., S.B.A.; Critical review - A.A., S.B.A.

\section{References}

1. Eller JL, Raslan AM, Burchiel KJ. Trigeminal neuralgia: definition and classification. Neurosurg Focus 2005;18(5):E3.

2. Kabatas S, Albayrak SB, Cansever T, Hepgul KT. Microvascular decompression as a surgical management for trigeminal neuralgia: a critical review of the literature. Neurol India 2009;57(2):134-8.

3. Lunsford LD, Sheehan JP. Intracranial Stereotactic Radiosurgery. Stereotactic Radiosurgery for Trigeminal Neuralgia. New York: Thieme Medical Publishers; 2016. p. 160-8.

4. Kondziolka D, Zorro O, Lobato-Polo J, Kano H, Flannery TJ, Flickinger JC, et al. Gamma Knife stereotactic radiosurgery for idiopathic trigeminal neuralgia. J Neurosurg 2010;112(4):758-65.

5. Kondziolka D, Lacomis D, Niranjan A, Mori Y, Maesawa S, Fellows W, et al. Histological effects of trigeminal nerve radiosurgery in a primate model: implications for trigeminal neuralgia radiosurgery. Neurosurgery 2000;46(4):971-6.

6. Lucas JT Jr, Nida AM, Isom S, Marshall K, Bourland JD, Laxton AW, et al. Predictive nomogram for the durability of pain relief from gamma knife radiation surgery in the treatment of trigeminal neuralgia. Int J Radiat Oncol Biol Phys 2014;89(1):120-6.

7. Marshall K, Chan MD, McCoy TP, Aubuchon AC, Bourland JD, McMullen KP, et al. Predictive variables for the successful treatment of trigeminal neuralgia with gamma knife radiosurgery. Neurosurgery 2012;70(3):566-72. 
8. Régis J, Metellus P, Hayashi M, Roussel P, Donnet A, Bille-Turc F. Prospective controlled trial of gamma knife surgery for essential trigeminal neuralgia. J Neurosurg 2006;104(6):913-24.

9. Maesawa S, Salame C, Flickinger JC, Pirris S, Kondziolka D, Lunsford LD. Clinical outcomes after stereotactic radiosurgery for idiopathic trigeminal neuralgia. J Neurosurg 2001;94(1):14-20.

10. Brisman R, Khandji AG, Mooij RB. Trigeminal NerveBlood Vessel Relationship as Revealed by High-resolution Magnetic Resonance Imaging and Its Effect on
Pain Relief after Gamma Knife Radiosurgery for Trigeminal Neuralgia. Neurosurgery 2002;50(6):1261-6.

11. Balamucki CJ, Stieber VW, Ellis TL, Tatter SB, Deguzman AF, McMullen KP, et al. Does dose rate affect efficacy? The outcomes of 256 gamma knife surgery procedures for trigeminal neuralgia and other types of facial pain as they relate to the half-life of cobalt. J Neurosurg 2006;105(5):730-5.

12. Sheehan J, Pan HC, Stroila M, Steiner L. Gamma knife surgery for trigeminal neuralgia: outcomes and prognostic factors. J Neurosurg 2005;102(3):434-41. 